\title{
Morphological and Ecological Adaptations, and Cytological Studies in Astragalus rhizanthus Royle ex Benth. (Papilionaceae), an Endemic to Himalayas
}

\author{
Puneet Kumar ${ }^{1 *}$ and Vijay Kumar Singhal ${ }^{2}$ \\ ${ }^{1}$ Botanical Survey of India, Northern Regional Centre, Dehradun-248 195, Uttarakhand, India \\ ${ }^{2}$ Department of Botany, Punjabi University, Patiala, Punjab, India
}

Received July 7, 2015; accepted March 29, 2016

\begin{abstract}
Summary In the present investigation, we examined the morphological and ecological adaptations, and male meiosis and pollen fertility in an endemic species of genus Astragalus, A. rhizanthus Royle ex Benth. from cold deserts of Lahaul-Spiti district of Himachal, Pradesh, India. The three populations from Lahaul Valley and one from Spiti Valley depicted the same meiotic chromosome number of $n=8$ in all the accessions. In three populations (Lahaul, Sissu, 3170m, Chandartal Lake, $4300 \mathrm{~m}$; Spiti, Lossar, $3900 \mathrm{~m}$ ), meiosis was normal resulting into cent percent pollen fertility. However, in the accession from Lahaul Valley (Koksar, $3140 \mathrm{~m}$ ) majority of the pollen mother cells (PMCs) showed normal chromosome behaviour during meiosis-I and II. While, 12.09\% PMCs showed the occurrence of chromatin material transfer involving 2-5 meiocytes during prophase-I, metaphases-I/ II, anaphases-I/II and telophases-I/II. Consequent to this, hypo- and hyperploid PMCs resulted. In certain cases, PMCs fused together to form syncytes which had two complements in the same cell. Pollen sterility was observed to be $9 \%$. The paper also discusses morphological and ecological adaptations that the species has adopted to cope with the harsh and hostile environmental conditions prevailing in the cold deserts of Lahaul-Spiti.
\end{abstract}

Key words Chromosome, Cytomixis, Cold deserts, Hypo- and hyperploid PMCs, Himalayas, Lahaul-Spiti.

Astragalus L. (Family: Papilionaceae), with ca. 25003000 species in the world, is considered the largest and most complex genus of angiosperms (Podlech 1986, Zarre and Podlech 1997, Chaudhary and Srivastava 2007) distributed in arid and temperate regions of the Northern Hemisphere and South America (Podlech 1986). In India, it has about 80-90 species, chiefly distributed in the temperate to alpine regions of the Himalayas with the main center of diversity in the cold deserts of Lahaul-Spiti (Himachal Pradesh) and Leh and Ladakh (Jammu and Kashmir) (Chaudhary and Srivastava 2007, Chaudhary et al. 2007). In the current study, we examined $A$. rhizanthus Royle ex Benth. for its chromosome counts, male meiosis, and pollen fertility. A. rhizanthus complex includes four closely related species, A. rhizanthus, A. candolleanus, A. malacophyllus and $A$. pindreensis which are distributed in the $\mathrm{Hi}-$ malayas from Afghanistan to Nepal and in India from Jammu and Kashmir to Uttarakhand (Podlech 1988). A. rhizanthus ssp. rhizanthus var. rhizanthus exhibits an enormous amount of morphological variation among different Indian populations (Chaudhary et al. 2008). Anand et al. (2010) used molecular tools to address the relationships among the aforementioned allied species of the A. rhizanthus Benth. complex from different parts

\footnotetext{
*Corresponding author, e-mail: puneetbotcyto@gmail.com DOI: $10.1508 /$ cytologia. 81.155
}

of the Indian Himalayas and found the highest degree of genetic similarity was observed within A. rhizanthus followed by $A$. malacophyllus, A. candolleanus and $A$. pindreensis. Indian women chew the roots of the taxon to stimulate lactation (Anand et al. 2010). Roots have also been used as a heat stimulant and for skin diseases in Kashmir and Ladakh regions (Kaul 1997). In the Pangi Valley of the Chamba district and Lahaul-Spiti, the species is used as fodder (Sood et al. 2001, Kumar and Singhal 2013, Rana et al. 2014a). Chaudhary et al. (2008) emphasized the significance of chromosome numbers in interpretation of phylogenetic relationships in Astragalus and also pointed towards strong correlations between its geographic distribution and chromosome numbers. However, this morphologically variable species is poorly known for its chromosome number and meiotic behaviour from cold deserts of Lahaul-Spiti. As the species is widely distributed in cold regions of India and no cytological data is available for the species from the study area, an attempt has been made to study the species on a population basis for cytomorphological variations if any.

\section{Materials and methods}

For the chromosome counts and meiotic studies, material of A. rhizanthus Royle ex Benth. was collected from the drier habitats of Lahaul Valley (Sissu, $3170 \mathrm{~m}$, 


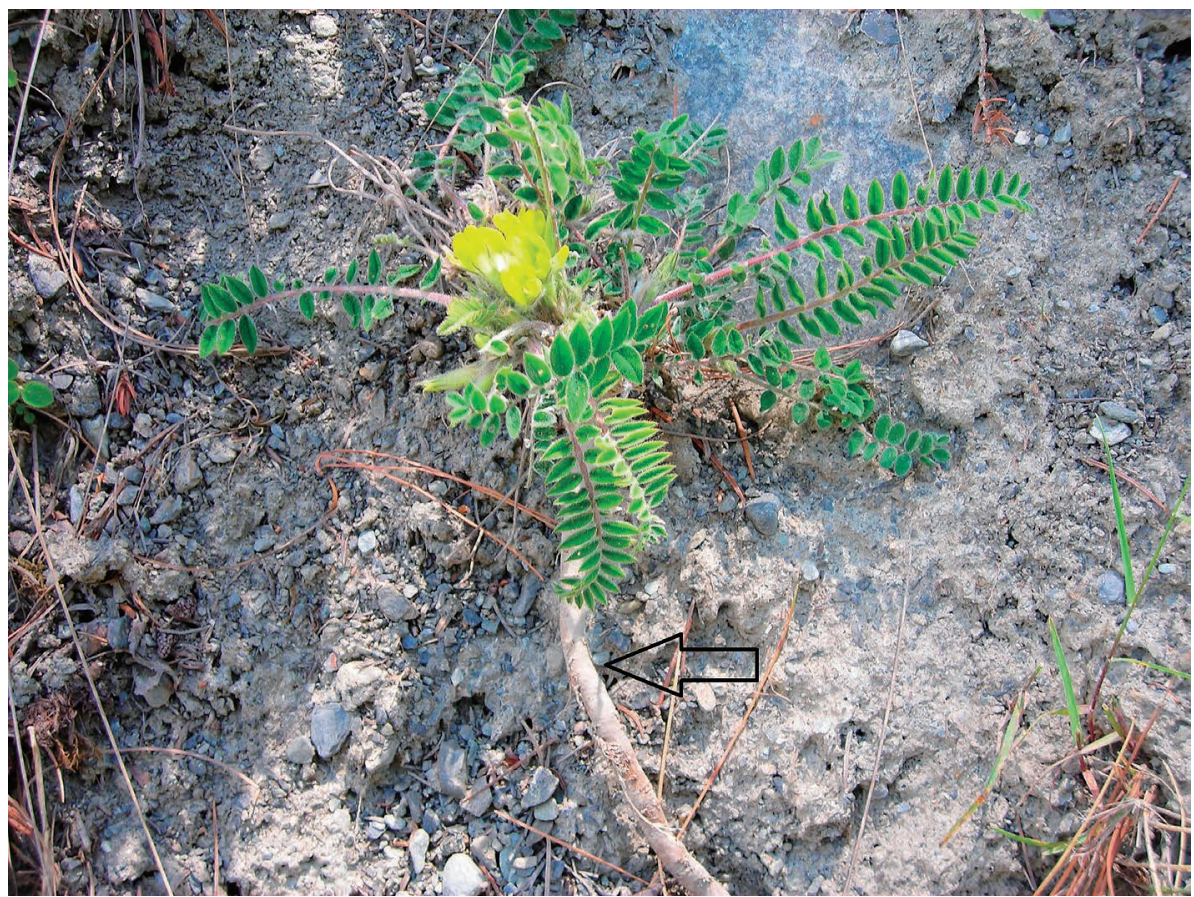

Fig. 1. A wild individual of Astragalus rhizanthus in its natural dry habitat showing long thick root (arrowed)

PUN51273; Chandartal Lake, 4300 m, PUN51275; Koksar, $3140 \mathrm{~m}$, PUN51203) and Spiti Valley (Lossar, $3900 \mathrm{~m}$ PUN51167) in Lahaul-Spiti district, Himachal Pradesh, India in June-July 2008. The young developing floral buds from healthy plants were fixed in freshly prepared Carnoy's fixative (6 absolute alcohol:3 chloroform: 1 glacial acetic acid, v:v:v) for $24 \mathrm{~h}$ and subsequently stored in $70 \%$ ethanol in a refrigerator until analysis. Developing anthers from floral buds were squashed in $1 \%$ acetocarmine and preparations were studied for chromosome counts, and detailed meiotic behaviour in pollen mother cells (PMCs) at prophase-I, metaphase-I (M-I), anaphases-I/II (A-I/II), telophases-I/ II (T-I/II) and sporad stage. A total of 50-100 PMCs were examined for determining the chromosome counts while 30-60 slides were prepared from different anthers/ flowers for analysis of chromosomal associations. Pollen fertility was estimated through stainability tests for which anthers of mature flowers were squashed in glycerol-acetocarmine mixture $(1: 1)$. A total of 200-500 pollen grains were analyzed in each case for pollen fertility. Well-filled pollen grains with uniformly stained cytoplasm were scored as fertile/viable while shrivelled ones with unstained or poorly stained cytoplasm were counted as sterile/unviable. Photomicrographs from the temporary mounts were taken using a Nikon Eclipse 80i microscope (Melville, U.S.A.).

\section{Results and discussion}

\section{Morphological and ecological observations}

The individuals of $A$. rhizanthus were growing in different localities and displayed observable differences owing to microclimatic conditions prevailing in the areas from which they were harvested. The habitats of the species are very hostile due to freezing temperature, dry climate, hard and rocky soils and the low ability of the soil to retain the moisture and high velocity of wind. The species has developed morphological and physiological adaptations such as hairs on leaves and young parts to counter the high wind velocity and high incidence of UV-rays as well as a deep root system (Figs. 1, 2 ), which provides ability to retain some moisture. The plants collected from the Sissu population were observed to be large with longer leaves and the individuals from the Chandartal Lake were quite dwarfed with reduced stems and small leaves. Other ecological and morphological adaptations include their ability to grow in very hard, dry and stony soils, the underground parts become perennial, woody, and deep rooted to acquire moisture and nutrition. These rootstocks are generally longer than upper part of the plants (Fig. 1) and may reach more than $0.30 \mathrm{~m}$ long. The longer rootstock provides these plants the ability to penetrate rock crevices and hard substratum and thus, the plants withstand the high wind velocity in higher altitudes. The plants are generally a stemless perennial herb and commonly grow on dry, stony or sandy riversides, amongst boulders, mountain slopes, and near agriculture fields and subalpine and alpine meadows up to altitudes of $3000-5500 \mathrm{~m}$.

\section{Chromosome count and male meiosis}

Presently, cytological studies have been performed in four accessions collected from different localities in Lahaul Valley and Spiti Valley. All the accessions uniformly exist at diploid level $(n=8)$ as confirmed by 


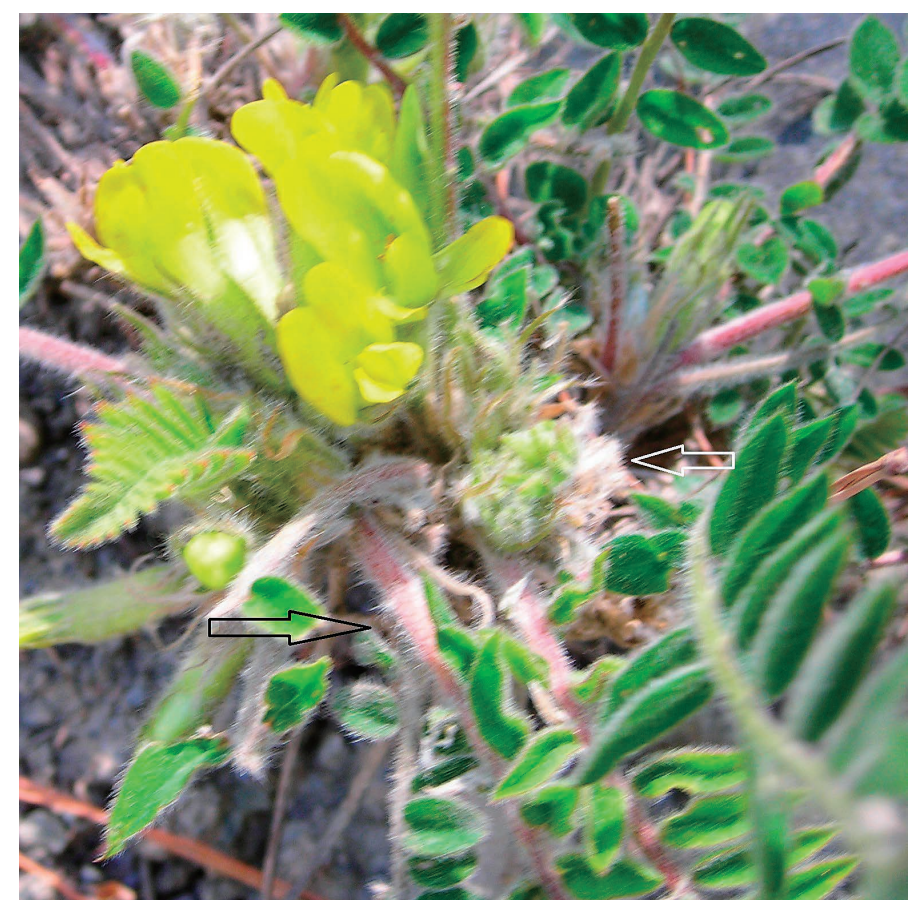

Fig. 2. A plant of Astragalus rhizanthus showing hairs on leaves and young parts (arrowed)

the presence of eight small sized bivalents at diakinesis (Fig. 3a) and M-I (Fig. 3b), 8:8 chromosomes distribution at A-I (Fig. 3c) and M-II (Fig. 3d). Meiotic course was recorded to be normal in the three accessions (Sissu, 3170 m; Lossar, 3900 m; Chandartal Lake, 4300 m) resulting into cent per cent pollen fertility. However, the accession scored from Koksar $(3140 \mathrm{~m})$ depicted interPMC transfer of chromatin material at various stages of meiosis from early prophase-I to T-II (Fig. 3e-i). Transfer of chromatin material involving 2-5 PMCs occurred in $12.09 \%$ cases. Chromatin transfer occurred through narrow and broad cytomictic channels forming a single chromatin strand. The resultant PMCs after chromatin transfer at T-II showed one, three and five haploid nuclei (Fig. 3i). Cytomictic channels without any transfer of chromatin material were also noticed in $7.19 \%$ cases. Another interesting observation of the present study is the transfer of nucleolus along with the chromatin material between meiocytes (Fig. 3f). Such transfer of nucleolus along with chromatin material during cytomixis had also been recorded in some other plants as well (Bhandari et al. 1969, Bhat et al. 2006, Kumar 2010, Kumar et al. 2014). Extra chromatin masses other than the normal complement were also noticed in some PMCs (Fig. 3j). In rare occasions, PMCs were directly fused to form syncytes (Fig. 3k). Transfer of chromatin material resulted in the formation of hypo- and hyperploid PMCs (Fig. 3i, j). Consequent to these meiotic irregularities, some pollen sterility $(9 \%)$ resulted in the accession (Fig. 31). The present meiotic chromosome count of $n=8$ in the species is in conformity with the earlier diploid records of $2 n=16$ from Meenamarg $(3325 \mathrm{~m})$ in Ladakh, Jammu and Kashmir (Ashraf and Gohil 1986, 1989, Gohil and
Ashraf 1989). These researchers have also reported the lagging of one chromosome at A-I and have attributed it to the failure of spindle apparatus. The occurrence of cytomixis and consequent pollen sterility is reported here for the first time in the species.

Cytomixis, which refers to inter-PMC transfer of chromatin material, has been observed to produce hypo-, hyperploid and enucleated PMCs and in extreme case, syncytes besides many other meiotic irregularities. Cytomixis induced meiotic irregularities and formation of hypo-and hyperploid PMCs has also been reported in several angiosperms (Omara 1976, Singhal and Gill 1985, Falistocco et al. 1995, Malallah and Attia 2003, Ghaffari 2006, Kumar and Singhal 2008, 2011, 2012, Kumar et al. 2008, 2010, 2011, 2012, 2014, 2015, Singhal and Kumar 2008a, b, 2010, Singhal et al. 2009, 2010, 2011a, b, 2014, Himshikha et al. 2010, Kumar 2010, Kaur and Singhal 2012, 2014, Kaur et al. 2013, Rana et al. 2013, 2014b, Mursalimov and Deineko 2011, 2012, 2015, Mursalimov et al. 2013a, b). The phenomenon of cytomixis does not seem to have affected the pollen fertility to a greater extent in current case. Similar results regarding the high pollen fertility in plants depicting cytomixis were reported in Dactylis (Falistocco et al. 1995). As individuals with and without cytomixis are found to grow in the same environmental conditions, cytomixis in $A$. rhizanthus seems to be a natural process of intercellular interaction under direct genetic control (Omara 1976, De and Sharma 1983, Singhal and Gill 1985, Lattoo et al. 2006; Singhal and Kumar 2008a, Kumar 2010, Kumar et al. 2010, Kravets 2012, Kumar and Singhal 2012, Mandal et al. 2013). 


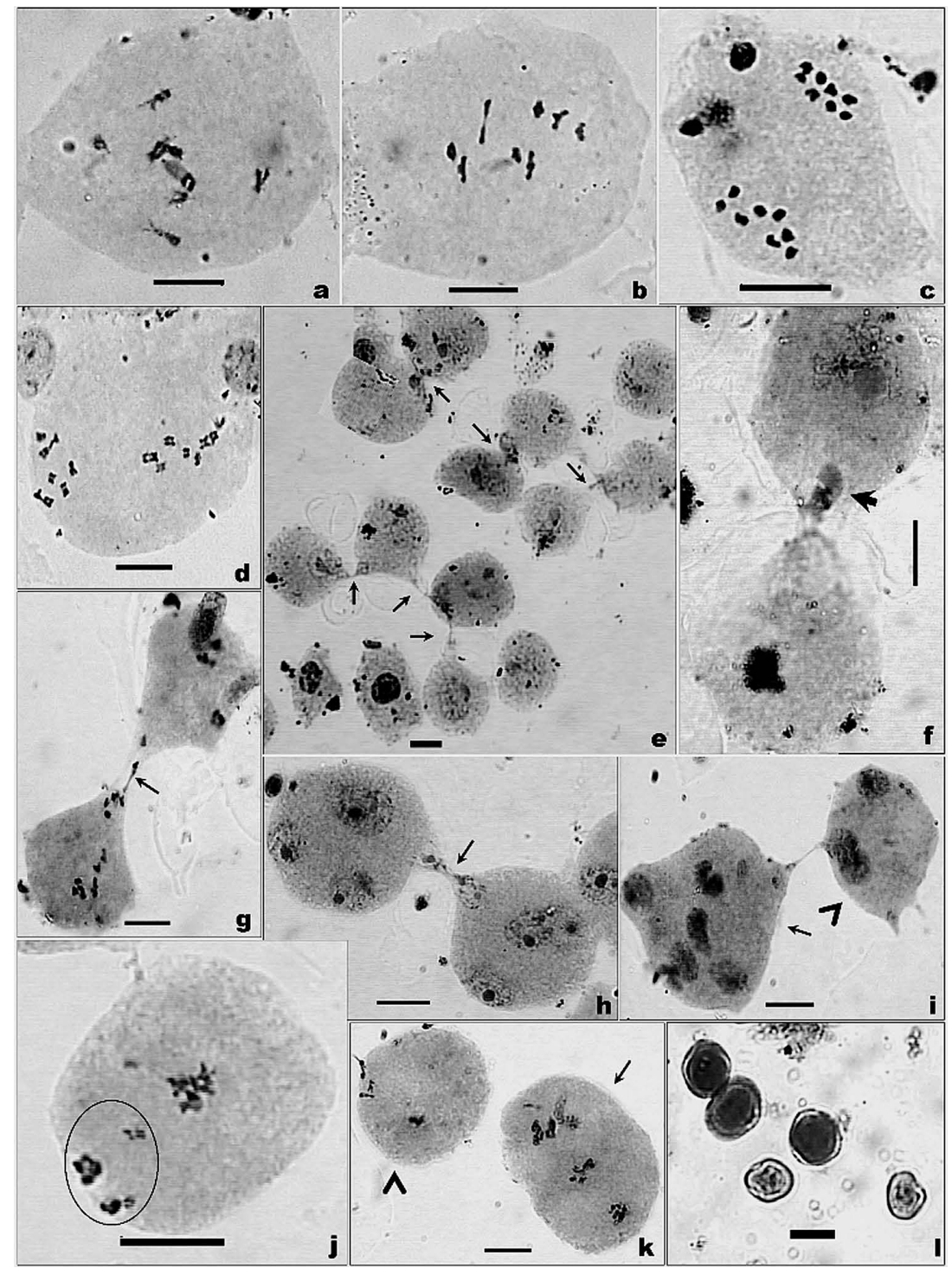

Fig. 3. (a-1) PMCs (pollen mother cells) showing meiotic chromosome numbers and meiotic abnormalities, and pollen grains. a) Diakinesis, $n=8$. b) Metaphase-I, $n=8$. c) Anaphase-I, 8:8 chromosomes distributions. d) Metaphase-II, $8: 8$ chromosomes distributions. e) Chromatin transfer (arrows) at early prophase-I. f) Chromatin as well as nucleolus (arrow) transfer at early prophase-I. g) Chromosome transfer (arrow) can be seen without forming agglutinated chromatin mass during migration through the cytomictic channels at metaphase-I. h) Chromatin transfer at lateT-II. i) Hypo- (arrowhead) and hyperploid (arrow) PMCs. j) Hyperploid PMC with extra chromatin material (encircled) at M-I. k) Syncyte (arrow) with double chromosome complement and a hypoploid PMC (arrowhead). 1) Apparently fertile (darkly stained) and sterile (shriveled and lightly stained) pollen grains. Scale bar $=10 \mu \mathrm{m}$.

\section{Acknowledgements}

The authors wish to thank the University Grants Commission (UGC), New Delhi, for providing financial assistance under DRS SAP I, II and III, and the ASIST Programme and Council of Scientific and Industrial Research (CSIR) for providing a senior research fellowship to the senior author. Further support was provided by the UGC under the Dr. D. S. Kothari Post-Doctoral Fellowship Scheme [Award Letter No. F.4-2/2006 (BSR)/13427/2011(BSR)] to Dr. Puneet Kumar. Thanks are also due to the Head, Department of Botany, Punjabi University, Patiala and Dr. Paramjit Singh Director, Botanical Survey of India, Kolkata and Head of Office, NRC, Deh- radun for necessary laboratory, herbarium (PUN, BSD) and internet facilities.

\section{References}

Anand, K. K., Srivastava, R. K. and Chaudhary, L. B. 2010. Analysis of genetic diversity in Astragalus rhizanthus Benth. ssp. rhizanthus var. rhizanthus (Fabaceae) using molecular markers from India. J. Bot. 2010: 1-9. Article ID 701975, doi: $10.1155 / 2010 / 701975$

Ashraf, M. and Gohil, R. N. 1986. Chromosome number reports 91. Taxon 35: 408.

Ashraf, M. and Gohil, R. N. 1989. Studies on the cytology of legumes of Kashmir Himalaya IV. Meiotic behaviour in 21 species of Astragalus L. Cytologia 54: 565-571. 
Bhandari, N., Tandon, S. L. and Jain, S. 1969. Some observations on the cytology and cytomixis in Canavalia DC. Cytologia 34: 22-28.

Bhat, T. A., Parveen, S. and Khan, A. H. 2006. MMS-Induced cytomixis in pollen mother cells of Broad Bean (Vicia faba L.). Turk. J. Bot. 30: 273-279.

Chaudhary, L. B., Anand, K. K. and Srivastava, R. K. 2007. Taxonomic study of endemic species of Astragalus L. (Fabaceae) of India. Taiwania 52: 216-237.

Chaudhary, L. B. and Srivastava, S. K. 2007. Taxonomic and distributional notes on some Astragalus L. (Fabaceae) in India. Taiwania 52: $25-48$

Chaudhary, L. B., Rana, T. S. and Anand, K. K. 2008. Current status of the systematics of Astragalus L. (Fabaceae) with special reference to the Himalayan species in India. Taiwania 53: 338-355.

De, M. and Sharma, A. K. 1983. Cytomixis in pollen mother cells of an apomictic ornamental Ervatamia divaricata (L.) Alston. Cytologia 48: 201-207.

Falistocco, E., Tosti, N. and Falcinelli, M. 1995. Cytomixis in pollen mother cells of diploid Dactylis one of the origins of $2 n$ gametes. J. Hered. 86: 448-453.

Ghaffari, G. M. 2006. Occurrence of diploid and polyploid microspores in Sorghum bicolor (Poaceae) is the result of cytomixis. Afr. J. Biotechnol. 5: 1450-1453.

Gohil, R. N. and Ashraf, M. 1989. Studies on the cytology of legumes of Kashmir Himalaya VI. Karyotypes and relationships in some Indian species of Astragalus L. Aspects Pl. Sci. 11: 375-382.

Himshikha, Kumar, P., Gupta, R. C., Kumari, S. and Singhal, V. K. 2010. Impact of chromatin transfer and spindle abnormalities on pollen fertility and pollen size in Plantago lanceolata L. Cytologia 75: 421-426.

Kaul, M. K. 1997. Medicinal plants of Kashmir and Ladakh: Temperate and Cold Arid Himalaya. Indus Publishing Company, New Delhi.

Kaur, D., Kumar, P. and Singhal, V. K. 2013. Chromosome counts and cytomixis in two species of Trigonella L. Cytologia 78: 235-242.

Kaur, D. and Singhal, V. K. 2012. Phenomenon of cytomixis and intraspecific polyploidy $(2 x, 4 x)$ in Spergularia diandra (Guss.) Heldr. \& Sart. in the cold desert regions of Kinnaur district (Himachal Pradesh). Cytologia 77: 163-171.

Kaur, M. and Singhal, V. K. 2014. First report of cytomixis and meiotic abnormalities in Nepeta govaniana from Solang Valley, Kullu District. Himachal Pradesh. Cytologia 79: 227-233.

Kravets, E. A. 2012. Nature, significance, and cytological consequences of cytomixis. Cytol. Genet. 46: 188-195.

Kumar, P. 2010. Exploration of cytomorphological diversity in the members of Polypetalae from Lahaul-Spiti and adjoining areas [Doctoral Dissertation]. [Patiala]: Punjabi University. http://hdl. handle.net/10603/2872. Accessed on 25 July 2015.

Kumar, P. and Singhal, V. K. 2008. Cytology of Caltha palustris L. (Ranunculaceae) from cold regions of Western Himalayas. Cytologia 73: 137-143.

Kumar, P. and Singhal, V. K. 2011. Chromosome number, male meiosis and pollen fertility in selected angiosperms of the cold deserts of Lahaul-Spiti and adjoining areas (Himachal Pradesh, India). Plant Syst. Evol. 297: 271-297.

Kumar, P. and Singhal, V. K. 2012. Erratic male meiosis resulting in $2 n$ pollen grain formation in a $4 x$ cytotype $(2 n=28)$ of Ranunculus laetus Wall. ex Royle. Scientific World J. 2012: 1-9. Article ID 691545, doi: 10.1100/2012/691545

Kumar, P. and Singhal, V. K. 2013. Ethnobotany and ethnomedicinal uses, chromosomal status and natural propagation of some plants of Lahaul-Spiti and adjoining hills. J. Bot. 2013: 1-14. Article ID 248943, doi: 10.1155/2013/248943

Kumar, P., Singhal, V. K. and Kaur, J. 2008. Cytomixis induced meiotic abnormalities in pollen mother cells of Clematis flammula $\mathrm{L}$.
(Ranunculaceae). Cytologia 73: 381-385.

Kumar, P., Singhal, V. K., Kaur, D. and Kaur, S. 2010. Cytomixis and associated meiotic abnormalities affecting pollen fertility in Clematis orientalis. Biol. Plant. 54: 181-184.

Kumar, P., Singhal, V. K., Rana, P. K., Kaur, S. and Kaur, D. 2011. Cytology of Ranunculus laetus Wall. ex Royle from cold desert regions and adjoining hills of North-west Himalayas. Caryologia 64: 25-32.

Kumar, P., Singhal, V. K. and Kaur, D. 2012. Impaired male meiosis due to irregular synapsis coupled with cytomixis in a new diploid cytotype of Dianthus angulatus (Caryophyllaceae) from Indian cold deserts. Folia Geobot. 47: 59-68.

Kumar, P., Rana, P. K., Himshikha, Singhal, V. K. and Gupta, R. C. 2014. Cytogeography and phenomenon of cytomixis in Silene vulgaris from cold regions of Northwest Himalayas (India). Plant Syst. Evol. 300: 831-842.

Kumar, R., Rana, P. K., Himshikha, Kaur, D., Kaur, M., Singhal, V. K., Gupta, R. C. and Kumar, P. 2015. Structural heterozygosity and cytomixis driven pollen sterility in Anemone rivularis Buch.-Ham. ex DC. from Western Himalaya (India). Caryologia 68: $246-253$.

Lattoo, S. K., Khan, S., Bamotra, S. and Dhar, A. K. 2006. Cytomixis impairs meiosis and influences reproductive success in Chlorophytum comosum (Thunb.) Jacq.: An additional strategy and possible implications. J. Biosci. 31: 629-637.

Malallah, G. A. and Attia, T. A. 2003. Cytomixis and its possible evolutionary role in a Kuwait population of Diplotaxis harra (Boraginaceae). Bot. J. Linn. Soc. 143: 169-175.

Mandal, A., Datta, A. K., Gupta, S., Paul, R., Saha, A., Ghosh, B. K., Bhattacharya, A. and Iqbal, M. 2013. Cytomixis: A unique phenomenon in animal and plant. Protoplasma 250: 985-996.

Mursalimov, S. R. and Deineko, E. V. 2011. An ultrastructural study of cytomixis in tobacco pollen mother cells. Protoplasma 248: 717-724.

Mursalimov, S. R. and Deineko, E. V. 2012. An ultrastructural study of microsporogenesis in tobacco line SR1. Biologia 67: 369-376.

Mursalimov, S. R. and Deineko, E. V. 2015. How cytomixis can form unreduced gametes in tobacco. Plant Syst. Evol. 301: 1293-1297.

Mursalimov, S. R., Sidorchuk, Y. B. and Deineko, E. V. 2013a. The role of spherosome-like vesicles in formation of cytomictic channels between tobacco microsporocytes. Biol. Plant. 57: 291-297.

Mursalimov, S. R., Sidorchuk, Y. B. and Deineko, E. V. 2013b. New insights into cytomixis: Specific cellular features and prevalence in higher plants. Planta 238: 415-423.

Omara, M. K. 1976. Cytomixis in Lolium perenne. Chromosoma 55: 267-271.

Podlech, D. 1986. Taxonomic and phytogeographical problems in Astragalus of old world and South-West Asia. Proc. R. Soc. Edinb. 89: 37-43.

Podlech, D. 1988. Revision von Astragalus L. sect. Caprini DC. (Leguminosae). Mitt. Bot. Staatssam. Munchen 25: 1-294.

Rana, P. K., Kumar, P. and Singhal, V. K. 2013. Spindle irregularities, chromatin transfer and chromatin stickiness on male meiosis and pollen grain formation in Anemone tetrasepala. Turk. J. Bot. 37: 167-176.

Rana, P. K., Kumar, P., Singhal, V. K. and Rana, J. C. 2014a. Uses of local plant biodiversity among the tribal communities of pangi Valley of District Chamba in cold desert Himalaya, India. Scientific World J. 2014: 1-15. Article ID 753289, http://dx.doi. org/10.1155/2014/753289.

Rana, P., Kumar, P. and Singhal, V. K. 2014b. Cytomixis and associated abnormalities during male meiosis in Lindelofia longiflora var. falconeri (Boraginaceae). Cytologia 79: 535-540.

Singhal, V. K. and Gill, B. S. 1985. Cytomixis in some woody species. Biologica 1: 168-175.

Singhal, V. K., Kaur, S. and Kumar, P. 2010. Aberrant male meiosis, 
pollen sterility and variable sized pollen grains in Clematis montana Buch. Ham. ex DC. from Dalhousie hills, Himachal Pradesh. Cytologia 75: 31-36.

Singhal, V. K. and Kumar, P. 2008a. Cytomixis during microsporogenesis in the diploid and tetraploid cytotypes of Withania somnifera (L.) Dunal, 1852 (Solanaceae). Comp. Cytogenet. 2: 85-92.

Singhal, V. K. and Kumar, P. 2008b. Impact of cytomixis on meiosis, pollen viability and pollen size in wild populations of Himalayan poppy (Meconopsis aculeata Royle). J. Biosci. 33: 371-380.

Singhal, V. K. and Kumar, P. 2010. Variable sized pollen grains due to impaired male meiosis in the cold desert plants of North West Himalayas (India). In: Benjamin, J. K. (ed.). Pollen: Structure, Types and Effects. Nova Science Publishers, New York. pp. 101-126.

Singhal, V. K., Kumar, P., Kaur, D. and Rana, P. K. 2009. Chromatin transfer during male meiosis resulted into heterogeneous sized pollen grains in Anemone rivularis Buch.-Ham. ex DC. from In- dian cold deserts. Cytologia 74: 229-234.

Singhal, V. K., Kumari, V. and Kumar, P. 2014. Cytomorphological diversity in some selected members of Poaceae from Parvati Valley in Kullu district of Himachal Pradesh, India. Plant Syst. Evol. 300: $1385-1408$.

Singhal, V. K., Rana, P. K. and Kumar, P. 2011a. Syncytes during male meiosis resulting in $2 n$ pollen grain formation in Lindefolia longiflora var. falconeri. J. Syst. Evol. 49: 406-410.

Singhal, V. K., Rana, P. K., Kumar, P. and Kaur, D. 2011b. Persistent occurrence of meiotic abnormalities in a new hexaploid cytotype of Thalictrum foetidum from Indian cold deserts. Biologia $\mathbf{6 6}$ : 458-464.

Sood, S. K., Nath, R. and Kalia, D. C. 2001. Ethnobotany of Cold Desert Tribes of Lahaul-Spiti (N.W. Himalaya). Deep Publishers, New Delhi.

Zarre, S. H. and Podlech, D. 1997. Problems in the taxonomy of tragacanthic Astragali. Sendtnera 4: 243-250. 